\section{Anomalisa e o ensino da comunicação clínica na prática médica}

\section{Anomalisa and teaching clinical communication in medical practice}

\section{Anomalisa y la enseñanza de la comunicación clínica en la práctica médica}

Bruno Pereira Stelet 1,2

Luis David Castiel 2

Danielle Ribeiro de Moraes 2

\title{
Resumo
}

Partindo de reflexões do filme Anomalisa e apoiando-se no conceito foucaultiano de biopoder, este ensaio discute os limites do ensino de habilidades de comunicação clínica na formação em medicina. A comunicação com pacientes não se relaciona ao uso (ou não-uso) de certas frases ou de determinado estilo de conversa, mas significa a busca de uma maneira de interagir com o outro em meio à desordem do mundo, à arrebatadora onda de sofrimento e ao intervalo de tempo assustador entre a vida e a morte. Nesse cenário em que figuram as tecnobiociências e imperam as evidências científicas, para além dos protocolos ou da padronização dos modos de se praticar a clínica, propõe-se um debate sobre o ensino da comunicação com ênfase na produção de subjetividades, de modo a veicular um chamamento à reflexão sobre valores desejáveis para a atuação no campo da saúde.

Comunicação em Saúde; Educação Médica; Relações Médico-Paciente

\section{Correspondência}

B. P. Stelet

Rua Humaitá 282, bloco 02, apto. 1103, Rio de Janeiro, RJ 22261-001, Brasil.

stelet@ufrj.br

1 Universidade Federal do Rio de Janeiro, Rio de Janeiro, Brasil. 2 Escola Nacional de Saúde Pública Sergio Arouca, Fundação Oswaldo Cruz, Rio de Janeiro, Brasil. 
"O que me interessa são as relações entre as artes, a ciência e a filosofia. Não há nenhum privilégio de uma destas disciplinas em relação a outra. Cada uma delas é criadora” 1 (p. 154).

\section{Introdução}

A interface entre comunicação e saúde no Brasil vem, desde os anos 1980, se constituindo como campo de produção de práticas e de saberes fundamentais no âmbito do Sistema Único de Saúde (SUS) 2, em especial na formulação de políticas, na democratização das tecnologias de informação e comunicação e nos estudos para a utilização das mídias na saúde 3 . Apoiados em Araújo \& Cardoso 4 , assumimos que comunicação e saúde são dois campos que se constituem mutuamente e, como práticas sociais, reverberam e são atravessados por outros campos, processos e contextos. A comunicação, portanto, não deve ser compreendida como simples transmissão de informações, mas como "permanente e disputado processo de produção, circulação e apropriação de sentidos sociais" 4 (p. 62). Tal perspectiva exige a "superação de práticas e modelos teórico-metodológicos de natureza instrumental, bipolar e unidirecional, que ignoram ou reduzem a complexidade dos processos relacionados aos sentidos da saúde" 4 (p. 63). Em outras palavras, nos estudos acerca da comunicação no escopo da relação entre pacientes e profissionais de saúde, ainda que incipientes no Brasil, nota-se que a comunicação está restrita como técnica integrada à entrevista clínica 5 .

A necessidade de uma "ampliação da clínica” por parte dos profissionais já se configura consolidada na Saúde Coletiva, ou seja, defende-se o alargamento de saberes e práticas para fazer caber aspectos psicológicos, culturais e sociais das pessoas e territórios atendidos, de forma a produzir uma abordagem mais singular dos sujeitos como um requisito estratégico para a construção do SUS 6,7,8. O debate sobre o Cuidado Integral em Saúde 9,10 também vem contribuindo para prestar novos significados às práticas profissionais e às relações entre os sujeitos, para a construção de um cuidado coerente com os princípios do SUS no cotidiano dos serviços. Ao mesmo tempo, tais estudos têm lançando desafios e fundamentos para o ensino-aprendizagem da comunicação em saúde e de valorização das subjetividades do encontro clínico.

Desde 2001, reafirmadas em 2014, as Diretrizes Curriculares Nacionais (DCN) para os cursos de graduação em Medicina orientam que a formação médica deve propiciar o desenvolvimento da habilidade de se comunicar adequadamente com os pacientes e da capacidade reflexiva e compreensão ética, integral e humanística da relação médico-paciente 11. No entanto, quando se busca a temática específica da comunicação com foco no ensino em saúde, encontra-se ainda pouca produção no país, afirma Dohms 12 ao realizar uma revisão sistemática sobre o assunto. Contudo, em outros países nos últimos 25 anos, têm sido desenvolvidos estudos e ferramentas a respeito do ensino de conhecimentos e habilidades comunicacionais na formação em saúde, em especial do profissional médico. O ensino de comunicação clínica é considerado parte fundamental do currículo médico na graduação de países como Inglaterra, Espanha, Holanda e Estados Unidos 12,13.

$\mathrm{Na}$ literatura internacional há uma vastidão de artigos e livros técnicos - poucos traduzidos para o português, com destaque para Carrió 14 - que aprofundam o tema das habilidades de comunicação e das técnicas para melhorar a relação entre profissional de saúde e paciente. Muitos desses livros de referência trazem um traço mais instrumental e pragmático, propondo modelos e ferramentas comunicacionais para melhorar o diálogo e a comunicação, em especial no âmbito ambulatorial. Carrió 14 (p. 13) afirma que sua publicação tem "o propósito reconhecido e claro de criar hábitos de trabalho. Mais do que falar de comunicação, pretende mostrar como fazer comunicação".

Ainda assim, interrogamos: melhorar o conhecimento e as habilidades de entrevista clínica é suficiente para a produção de um cuidado em saúde mais integral? Concordamos com Mattos 15 que o termo "integralidade" enseja diferentes sentidos que vão desde as atitudes e práticas do profissional de saúde até os modos de organização dos serviços e processos de trabalho, até a configuração de políticas específicas como respostas governamentais a certos problemas, demandas ou necessidades de saúde de grupos populacionais. Isto é, a prerrogativa do provimento do cuidado integral relaciona-se diretamente à garantia de acesso aos serviços por parte da população, à articulação dos sistemas locais de saúde e, dentre outros fatores, ao financiamento de políticas que garantam o direito constitucional à saúde. 
Neste ensaio, propomo-nos a refletir sobre a seguinte pergunta: é possível exercitar o cuidado em saúde, ou o "encontro clínico", enquanto treinamento de habilidades? Ou ainda, até que ponto o treinamento de técnicas de comunicação tornam as práticas de saúde mais dialógicas?

\section{Intercessores e Anomalisa}

A epígrafe deste trabalho faz referência ao pensamento de Gilles Deleuze. Justifica-se inicialmente porque partimos da compreensão de que as artes, a filosofia e a ciência estabelecem relações de efeitos, "percutem uma na outra" 1 (p. 156), produzem ressonâncias mútuas que interferem entre si. Interferir não significa trocar, compartilhar, vigiar ou refletir reciprocamente. Antes, interferir seria interceder: "a criação são os intercessores" 1 (p. 156).

Apesar de Deleuze não ter desenvolvido explicitamente o conceito de intercessores, a ideia atravessa sua obra. Foi em uma entrevista a Antoine Dulaure e Claire Parnet que Deleuze apontou indícios para a conceituação do termo ${ }^{1}$. O autor enuncia que os conceitos são movimentos constituídos a partir de encontros, experiências ou problemas que impelem o pensamento a ser pensado. Os intercessores consistiriam, então, em agenciadores do pensamento.

Uma segunda referência a Deleuze aqui utilizada é o Cinema em si. Decerto que o Cinema consistiu (e consiste) em objeto de estudo de diversos campos do conhecimento, desde a filosofia, a psicanálise e mesmo as teorias narrativas. No entanto, para Deleuze, o Cinema não é somente um objeto de reflexão teórica, mas constitui um campo de conhecimento que, sendo arte, ecoa em (e é ecoada por) diferentes linhas melódicas como a filosofia e a ciência 16 .

No sentido deleuziano, tomaremos como intercessores no caso deste texto o filme norte-americano Anomalisa 17. Esse filme é uma obra ficcional lançada no Brasil em janeiro de 2016 e dirigida pelo norte-americano Charlie Kaufman - que também participou da roteirização, direção e/ou produção de outros filmes como Quero ser John Malkovich e Adaptação. O filme Anomalisa parece utilizar um tom irônico (e, por vezes, cômico) para tecer uma aguçada crítica à nossa atualidade. O personagem principal é Michael Stone, um famoso escritor de autoajuda para trabalhadores da área de "atendimento ao cliente", que viaja até Cincinnati (Estados Unidos) para divulgar o lançamento de seu novo livro - um tipo de manual que promete a seus leitores quase dobrar as vendas em suas empresas apenas usando técnicas de comunicação, cujo meio é fazer com que o cliente se sinta como indivíduo "único e especial". A ironia vai se concretizando até o clímax "epifânico" (a la Clarice Lispector) durante sua palestra, quando o próprio Michael percebe que não acredita em suas pregações, não conseguindo, portanto, comunicar bem suas ideias.

O filme foi gravado em stop-motion, uma animação que provoca um primeiro estranhamento pelo fato de os personagens serem "bonecos", como caricaturas de humanos. Apesar de possuírem a textura da pele e os movimentos parecidos com um humano "real" - fazendo uso do desenho gráfico e digital do filme - os bonecos aparentam usar "máscaras humanas" como estratégia de acabamento para esconder uma estrutura robótica (ou maquínica) subjacente. Em certa medida, os personagens do filme seriam humanos-robôs com máscaras humanoides - todos com praticamente o mesmo traço fisionômico.

Essa espécie de metáfora da padronização do ser humano ganha materialidade também nos cenários do filme, pois tanto o aeroporto quanto o hotel, onde se passa a maior parte da história, mais parecem não-lugares cuja decoração-padrão poderia ser como a de qualquer "hotel-business" ou aeroporto do mundo. Essa estética "standardizada" é corroborada pelo curioso fato de todos os personagens terem um timbre de voz igual (dublado por uma mesma voz masculina), exceto a personagem Lisa, uma anomalia.

A anomalia de Lisa ultrapassa sua voz feminina. Lisa está no mesmo hotel que Michael porque ela é uma atendente de telemarketing que foi assistir à palestra de lançamento do livro do autor, mas não age de maneira convencional para o cenário. Exemplo disso é uma cena que evidencia um certo desencaixe social naquele ambiente em que Lisa tropeça e cai no corredor do hotel. Lisa age espontaneamente, é insegura, mostra cicatrizes, desejos, medos... Enfim, revela-se de maneira mais "humana" que os outros personagens que terminam compondo o cenário sempre asséptico, organizado e robotizado. 
Os diálogos entre Michael e Lisa expressam sentimentos, sonhos e imaginação - uma esperança de relação genuína para os personagens. Já as conversas entre Michael e o taxista ou o recepcionista do hotel são superficiais e regradas, como se estivessem seguindo um certo roteiro adequado à esterilidade do cenário. Frases como "Por aqui, senhor", "Pois não, senhor", "O senhor é o cliente" são usadas pelos funcionários do hotel cujo gerente se apresenta como ávido leitor dos livros de Michael.

Não parece haver uma tomada de consciência de Michael em relação ao mundo que o circunda. Há, no entanto, um constante mal-estar e uma angústia que se expressam na solidão e na superficialidade das relações, incluindo suas relações familiares.

\section{Anomalisa e biopoder}

Em certa medida, o filme imita um retrato caricatural e sensível de como o poder disciplinar que, conforme Foucault 18, pode estar embrenhado em todas as esferas da vida e as movimenta para que se mantenha disperso molecularmente nas relações entre os sujeitos - e dos sujeitos com o mundo. Pelbart 19 afirma que o poder penetrou todas as dimensões da existência humana, desde os genes, o corpo, a afetividade, a inteligência e até a imaginação foi violada e colonizada pelos poderes disciplinares. $\mathrm{O}$ que talvez seja relativamente novo é que, para além do controle dos corpos, esses poderes são exercidos também de maneira positiva, isto é, "investindo a vitalidade social de cabo a rabo, intensificando-a, otimizando-a e ao mesmo tempo monitorando-a por dentro, pilotando-a" 19 (p. 20).

A ideia de biopoder, a partir da segunda metade do século XVIII, correspondeu à concepção de população muito afeita à epidemiologia: um conjunto de indivíduos que são configurados como entidades passíveis de descrição mediante mensurações quantificáveis em suas relações com o seu meio e, portanto, controláveis em nome de sua saúde e/ou segurança.

A imagem de "população", traduzida em dados demográficos para intervenções sanitárias, se sintoniza à metáfora do rebanho. Essa aproximação nos parece afim às estratégias empregadas na organização, disposição e controle dos indivíduos mediante a noção de tecnologia individualizante de poder designada como "poder pastoral".

A analogia do rebanho conduzido pelos pastores era concebida como uma maneira de retratar as relações de poder entre aqueles que governam e os que são governados. É notório como a relação entre "pastor" e "rebanho" vai crescer no âmbito do Cristianismo - uma vez que já existia entre os hebreus - e irá configurar, assim, seu valor ético no contexto da civilização judaico-cristã.

Não à-toa, pode-se cogitar que a relação da figura pastoral com o seu rebanho se estilizou com o exercício comunicacional de biopoder dos pregadores da promoção de saúde diante da audiência das muitas tecnologias de informação e comunicação que procuram responsabilizar aqueles que não se autocontrolam diante de certos "estilos de risco", que não primam por virtudes cardeais como a prudência, temperança, fortaleza 20.

Mas, o biopoder deve ser encarado mais como uma perspectiva do que um conceito, no sentido de constituir um espectro de iniciativas mais ou menos racionalizadas desenvolvidas por autoridades para intervir no âmbito da vitalidade humana - seu nascimento, desenvolvimento, adoecimento e morte 21. Para efeitos analíticos, Rabinow \& Rose 22 postulam três elementos que constituem o biopoder: o conhecimento dos processos vitais; as relações de poder que tomam como objeto os seres humanos; e os modos de subjetivação por meio dos quais os sujeitos operam sobre si mesmos como seres vivos.

O próprio Foucault 23 explicita o modo como o biopoder se relaciona a questões referentes a taxas de nascimento e aos primórdios das respectivas políticas de intervenção; questões de morbidade, não tanto epidêmicas, mas os agravos à saúde usualmente prevalentes nas populações e que demandam intervenções em termos de saúde pública e assistência médica; problemas ligados aos idosos e acidentes passíveis de abordagens securitárias; problemas ligados à raça e os correspondentes efeitos, especialmente urbanos, das condições geográficas, climáticas e ambientais.

Da mesma forma, podemos nos referir a um biopoder que irá configurar práticas clínicas, se considerarmos as características básicas que definem o objeto das disciplinas do âmbito médico-sanitário. O biopoder médico ocupa um lugar hegemônico no confronto das definições que se autorizam para estabelecer as decisões quanto ao rumo "correto" das políticas, dos arcabouços administrativos, legais 
e institucionais e das ações, baseados nos padrões ditados pela expertise técnica vigente. Mais ainda, o biopoder médico participa ativamente na geração de uma cultura científica que configura o nosso pensamento e a ideia que a sociedade moderna tem a seu respeito, com base em distribuições de normalidade sustentadas pela curva normal gaussiana 24 .

\section{Anomalisa e anomalia}

Inúmeros outros diretores do Cinema, certamente interferidos pela filosofia foucaultiana, demarcaram a colonização dos poderes disciplinares na trama cotidiana de personagens em instituições (escolas, manicômios, prisões...). Mas o que sobressai em Anomalisa é a marca de tais poderes (mercadológicos, empresariais) na comunicação. A animação proporciona ao espectador a tragicômica caricatura de nós mesmos, personagens massificados e igualados à mesma fisionomia e ao mesmo timbre de voz, com suas singularidades solapadas às mesmas frases feitas, reproduzindo o senso comum exposto nas mídias e nas estratégias de marketing do mundo empresarial. O mal-estar de Michael fica evidente quando ele percebe os efeitos de seu livro no serviço prestado pelo bem treinado pessoal do hotel: a comunicação eficiente, robótica e burocrática.

$\mathrm{O}$ argumento da comunicação nos serve de intercessores neste ensaio em que propomos reflexões e diálogos, de modo a buscar uma forma de "tradução" destes elementos para o campo da Saúde Coletiva, em especial no âmbito da formação médica.

Em Anomalisa os humanos são representados por bonecos-robôs mascarados de humanos. Em dada cena, tomado por um mal-estar súbito ao se olhar no espelho, Michael deixa mostrar a estrutura metálica por debaixo da máscara humana. A metáfora dos autômatos utilizada como recurso gráfico não se limita à robotização do humano, mas na padronização da maneira de se relacionar e de reconhecer o outro.

O uso de bonecos-robôs representando humanos nos remeteu à controversa hipótese do Uncanny Valley (em tradução livre, "Vale da Estranheza"). Uncanny Valley consiste em uma suposição do campo da robótica e da animação 3D que postula o seguinte: quando as características (aparência e movimentos) de um robô se aproximam de seres naturais - mas não são de maneira muitíssimo similar - é provocada uma resposta de repulsa entre observadores humanos. O "vale" refere-se ao mergulho da curva no gráfico de nível de conforto que seres humanos referem em relação à verossimilhança estética de robôs 25. O conceito foi introduzido pelo professor japonês de robótica Masahiro Mori em 1970, e recentemente tem sido analisado por pesquisadores de outros campos como psicologia e sociologia relacionadas aos estudos comportamentais de empatia.

A hipótese original de Mori diz que, à medida em que um robô mais se parece com um ser humano, a resposta afetiva do observador humano em relação ao robô vai se tornando mais empática, até determinado ponto em que a resposta rapidamente se torna repulsiva. Entretanto, ao passo que a aparência do robô continua a ser menos distinguível de um ser humano, a resposta emocional passa a ser positiva novamente e finalmente se aproxima do nível de empatia entre dois humanos reais 26.

Apesar de ser uma hipótese ainda questionável na literatura científica 25 , é interessante tomá-la também como intercessores, como fez Gardner 27 numa forma de eco entre a robótica e a medicina. Em uma narrativa, Gardner 27 relata brevemente sobre uma experiência quando ainda era estudante do ensino médico. A narrativa trata da internação de seu pai em uma unidade coronariana, após um infarto do miocárdio, e reflete sobre como foi a abordagem da médica que o assistia:

"A médica que estava de plantão durante a semana em que meu pai passou na unidade de cuidados intensivos era jovem, focada e cheia de energia. Nas poucas conversas breves que tivemos, ela usou muitas frases que eu reconheci da escola de medicina. Mas sua abordagem não podia esconder o fato de que ela preferia estar olhando para a tela do seu 'smartphone' a falar comigo ou com minha mãe; na verdade as frases repetitivas que ela usava enfatizou isto. Em dado momento, ela desajeitadamente ofereceu uma caixa de lenços em nossa direção, embora nenhum de nós estivesse chorando" 27 (p. 1032, tradução nossa).

Chama atenção na narrativa o pressuposto de que a médica tenha sido treinada em "comunicação de más notícias", pois o uso correto da técnica foi realizado. Porém, isso não impediu que ruídos de comunicação fossem emitidos. 
Apesar da habilidade em lidar com situações em que é preciso dar más notícias seja cada vez mais enfatizada no ensino médico, especialmente pelo uso de variações do renomado protocolo Spikes 28 difundido inclusive no Brasil 29 , ainda que timidamente - o uso do protocolo nessa situação não foi suficiente para comunicar a má notícia da melhor maneira. Talvez o que de fato evidenciou a falta de empatia da médica para com os familiares tenha sido a atitude automática (por que não burocrática ou robótica?) de oferecer lenços de papel quando não era necessário. Notem que oferecer lenços de papel está presente na maioria dos manuais de treinamento de habilidades em comunicar más notícias.

A despeito do lapso da comunicação não verbal, fica claro o descompasso entre o que a médica falava e o que aparecia em suas atitudes. Ela parecia falsamente implicada com o sofrimento do outro, apesar de ter seguido o protocolo técnico. Seguimos em direção ao "Vale da Estranheza": o que mais se poderia sentir por algo cuja forma sugere a promessa de interação humana recíproca, mas que, ao mesmo tempo, percebemos que não é real? Robôs mascarados de seres humanos e padronizados pelo mesmo timbre de voz e fisionomia, como no filme Anomalisa?

A comunicação com pacientes não se relaciona ao uso (ou não-uso) de certas frases ou de determinado estilo de conversa, mas significa a busca de uma maneira de interagir com o outro em meio à desordem do mundo, à arrebatadora onda de sofrimento e ao intervalo de tempo assustador entre a vida e a morte.

De algum modo, a padronização de atitudes, exposta no filme Anomalisa, encontra eco na emergência de protocolos clínicos voltados à “comunicação de más notícias". Vale pensar que a protocolização dessas práticas não dá conta da experiência de finitude, tampouco garante que o profissional de saúde se disponha a acolher, em alguma medida, os efeitos dessa experiência vivida pelos pacientes/ usuários. Diante disso, cabe questionar a quem serve a protocolização de uma suposta empatia. Essa questão surge, sobretudo, se tivermos em mente a tendência privatista sobre a prática (e o ensino da) clínica, por um lado, e a também crescente judicialização das relações médico-paciente, por outro. É importante pontuar que a proliferação de protocolos clínicos e comunicacionais não dá conta de suportar a experiência de sofrimento, justamente porque estes não se dirigem ao âmbito afetivo, emocional, existencial, produtor de perplexidades em que reside a questão da finitude humana, constituindo-se, portanto, como obstáculo ao encontro clínico. Por outra perspectiva, tais protocolos apresentam-se como redutores de risco e podem criar certa ilusão de "segurança do paciente", quando, muitas das vezes, são utilizados para proteger o profissional, que aloja-se blindado à implicação e à afetação - condições estas necessárias para o cuidado em saúde.

\section{Empatia e anomalia}

Certamente há atitudes e palavras que melhor expressam empatia do que outras. De toda forma, empatia consiste em uma habilidade (ou um valor?) desejável nas relações de cuidado em saúde e deve ser um tema continuamente desenvolvido e debatido dentro das escolas médicas 30 e nos serviços de saúde. Mesmo assumindo que a empatia seja um dos elementos que compõem a comunicação clínica, Schweller 30 aponta a polissemia do termo: um traço da personalidade do profissional, uma habilidade, o uso como elemento terapêutico, um atributo cognitivo ou mesmo uma emoção. Segundo o autor, havia uma inconsistência conceitual que dificultava a realização de pesquisas e a interpretação de dados.

No debate entre os significados atribuídos à palavra empatia, pode-se notar também uma disputa de poder no campo: de um lado, cognitivistas como Hojat et al. ${ }^{31}$ postulam que a empatia seja a percepção intelectual sobre as preocupações do outro; há também os autores como Eisenberg 32 que enfatizam a dimensão afetiva, como uma certa resposta emocional perante as experiências do outro.

Se deslocarmos o debate para a arena da Educação Médica, não seria possível assumir a comunicação clínica apenas como mero treinamento de habilidades, na medida em que o processo educativo em geral não se dá nem pelo simples acúmulo de conhecimento - como se fosse uma síntese eficiente capaz de integrar as várias partes do conhecimento ou um aumento da capacidade de processar informações, como impinge o paradigma cognitivista da educação; tampouco pode-se adotar a educação apenas pela efetivação de competências - como se o aprender fosse uma técnica superdimensionada, 
esvaziada de significados, como nas pedagogias tecnicistas. Torna-se fundamental pensar sobre a produção de subjetividades nas relações pedagógicas 33 .

A produção de subjetividades na formação médica ainda está nas sombras do que se convencionou chamar de "currículo oculto", que inclui desde as influências advindas dos meios de comunicação de massa e que circulam como socialmente aceitos, até o resultado das relações sociais estabelecidas com integrantes ou não da comunidade médica 34 . O currículo oculto, como o próprio termo aponta, não aparece claramente nas grades curriculares ou nos objetivos de aprendizagem das disciplinas, mas relaciona-se diretamente ao desenvolvimento de valores dos futuros médicos. A aprendizagem do "ser médico", apesar de muitas vezes invisível nos currículos, opera no conhecimento tácito à beira do leito, nas consultas supervisionadas, nas sessões clínicas e na maneira de como se estabelece a comunicação com o outro, seja com o paciente ou outros profissionais de saúde 35 .

Bonet 36 afirma que a prática médica é marcada por uma certa ambiguidade em relação ao que o médico deve saber e ao que sente ao fazer. "Fazer" e "sentir" seriam expressões de uma tensão estruturante no interior do trabalho médico. $\mathrm{O}$ autor aponta que durante os anos de formação o estudante precisa ir manejando essa tensão. No entanto, por conta da racionalidade científica moderna constituinte da Biomedicina, gradativamente as expressões relacionadas à subjetividade, ao afetivo, vão sendo excluídas da prática cotidiana. A título de exemplo citamos o momento de construção do diagnóstico, quando surgem sentimentos, incertezas, tentativas e erros - inerentes à clínica - que parecem desaparecer ao final, quando o diagnóstico ganha estatuto de científico. A pretensa objetividade anula a subjetividade do processo.

Embora a Biomedicina tenha buscado epistemologicamente se aliar ao modelo científico, o médico em sua prática clínica não consegue cumprir este ensejo, já que a subjetividade se apresenta na sua experiência adquirida, nas interpretações dos exames físico e complementar, ao tomar decisões e exercitar julgamentos clínicos 37.

Para Schraiber 38, a medicina tecnológica, que vem sucedendo a medicina liberal (ainda vigente) após os anos 1960, tem como base a tensão entre cientificidade e pragmatismo. Buscando reduzir as dúvidas diante do incerto, que é a doença no outro, e em função de certa segurança ao basear sua prática nas ciências, "médicos e pacientes assim afastam seus medos da intervenção: o médico, de errar (...) e o paciente, de morrer ou piorar sua condição vital" 38 (p. 118).

Em 1966, Georges Canguilhem 39 se questionava sobre a pretensão científica da medicina, analisando como tinham sido constituídas as categorias "normalidade" e "patologia" na emergência de campos como a Fisiologia e a Fisiopatologia: "A medicina nos pareceria, e nos parece ainda, uma técnica ou arte situada na confluência de várias ciências, mais do que uma ciência propriamente dita" 39 (p. 10).

Partindo de uma discussão etimológica, com o objetivo de explorar os sentidos atribuídos à ideia de "normal" e "patológico", Canguilhem aponta que, na Medicina, estas definições são veladas ou se constituem numa perspectiva mais operativa do que conceitual. Essa divisão também se reflete na organização do saber médico construído, no qual por vezes se formam pares de disciplinas homólogas divididas em domínios de "normalidade" ou de "patologia". Isso posto, a noção de anomalia emerge nas reflexões de Canguilhem numa tentativa de contrastá-la com um ideal de "normal", que serve de parâmetro epistêmico tanto para identificar o que é patológico quanto como padrão a ser restaurado por meio de técnicas terapêuticas. O médico e filósofo francês nos mostra que os termos anomalia e anormal se aproximam por meio de uma confusão semântica:

"Anomalia vem do grego anomalia, que significa desigualdade, aspereza; omalos designa, em grego, o que é uniforme, regular, liso; de modo que anomalia é, etimologicamente, anomalos, o que é desigual, rugoso, irregular (...). Ora, frequentemente houve enganos a respeito da etimologia do termo anomalia derivando-o não de omalos, mas de nomos, que significa lei, segundo a composição a-nomos. (...) Ora, o nomos grego e o norma latino têm sentidos vizinhos, lei e regra tendem a se confundir" 39 (p. 50).

Canguilhem associa "anomalia" à variabilidade dos organismos vivos ou a um "desvio a partir de um tipo específico, definido por um grupo dos caracteres mais frequentes em sua dimensão média” 39 (p. 56). E é exatamente nessa construção de uma "realidade estatística", forjada na fisiologia patológica acerca do que seja normal ou patológico, que o autor vai situar suas reflexões.

No entanto, podemos notar que no pensamento canguilhemiano há uma normatividade inerente à vida ao mesmo tempo em que se postula uma relatividade individual desta normatividade biológica. A categoria "vida", conforme apreendida por Czeresnia 40 , é assinalada como uma ordem de proprie- 
dades e uma hierarquia de funções cuja estabilidade é necessariamente precária, permitindo que a irregularidade, a anomalia, em vez de acidente, seja concebida como condição singular do indivíduo. Ou seja, a singularidade anômala, ao invés de ser interpretada como fracasso frente à normalidade, passa a ser vista como uma contingência pela afirmação da própria vida.

A anomalia somente será concebida como patológica quando suas normas tornarem-se inferiores à estabilidade, fecundidade e variabilidade da vida e forem percebidas pelo organismo num dado meio. Caso contrário, a anomalia constituirá apenas uma variação, um exemplo da diversidade das normas na ordem biológica.

Aí parece situar a anomalia da personagem Lisa: ter uma voz singular em meio à padronização típica de um contexto "neoliberalizado". No filme Anomalisa parece haver uma norma para a produção de subjetividades dos personagens, como se o paradigma daquele mundo ficcional fosse a padronização dos gestos, das conversas e - num recurso radical dos diretores - a igualização da fisionomia e das vozes, ou seja, o timbre de voz, considerado característica singular e única de cada pessoa, é apresentado na película como praticamente o mesmo. Exceto a voz dos personagens principais Lisa e Michael.

Dardot \& Laval 41, seguindo os estudos de Foucault sobre "governamentalidade", analisam o neoliberalismo como racionalidade não apenas política e econômica, mas como forjadora de formas de subjetivação. O indivíduo "empreendedor de si" deve lançar mão das técnicas de comunicação para ser mais eficaz e produtivo, não apenas dentro do ambiente empresarial, mas no âmbito geral das relações interpessoais. Michael é um coaching que ensina técnicas que visam à conduta de si e dos outros, apontando essencialmente para o aumento da eficácia da relação com o outro, numa espécie de "pragmática da eficácia comunicacional" 41 (p. 341).

A voz e a fisionomia de Anomalisa, como o próprio nome ironicamente empregado quer dizer, são anomalias num contexto paradigmático de padronização. À guisa de comentário aparentemente digressivo, cabe ainda assinalar que "anomalia" e "paradigma” são dois conceitos fundamentais na epistemologia kuhniana que nos ajudarão na argumentação de que a maneira excessivamente protocolar com que se discute a comunicação na clínica é mais uma apropriação da Biomedicina em prol da manutenção do paradigma científico. Vale assinalar que, ao apoiar-se no estatuto científico, a Biomedicina opera na perspectiva do biopoder, ocupando um importante lugar na reprodução social 21,23.

\section{Anomalia paradigmática para uma conclusão anômala}

Há muitas acepções referidas ao sentido da consagrada expressão "paradigma”. E, sobretudo, assumese o fato dela ter se tornado um clichê, já há um bom tempo. Da mesma forma, sucede com as discussões de múltiplas rupturas. Mas aqui nos interessa a sua relação com a ideia kuhniana de "anomalia" 42. De todo o modo, pode-se tomar a liberdade de se considerar "paradigma”, para efeitos de nosso raciocínio, oxalá sem maiores diatribes, como modelos e padrões aceitos consensualmente e praticados em uma comunidade científica. Tal prática seria envolvida por teorias e leis compartilhadas interpares e que dirige o trabalho dos cientistas à consolidação de uma "ciência normal", ou seja, os cientistas que se dedicam à ciência normal estão lapidando e consolidando o paradigma vigente e, mesmo sem se dar conta, trabalham para a sua manutenção.

Segundo Kuhn 42, o cientista "normal” soluciona quebra-cabeças que podem ser resolvidos pelo paradigma vigente - e os seus membros são estimulados a fazê-lo. O fazer-ciência não incluiria novos fenômenos, tampouco a invenção de novas teorias.

No geral, as regras do trabalho do cientista estão implícitas, exceto quando os paradigmas se mostram inseguros, ou seja, quando as anomalias são "muitas e indomáveis", resistindo ao trabalho do cientista em enquadrá-las nos preceitos do paradigma. Nos períodos em que está para ocorrer uma substituição paradigmática é constante a indagação sobre os métodos, soluções de problemas e os procedimentos da ciência normal. O surgimento de um paradigma aconteceria quando houvesse uma síntese capaz de cativar grande parte de seus praticantes, em especial as novas gerações.

Novas descobertas são processos lentos e demorados, iniciados pela consciência de uma anomalia, ou seja, com o reconhecimento por parte dos cientistas de que a natureza violou as expectativas paradigmáticas que governam a ciência normal ${ }^{42}$. A anomalia gera insegurança nos cientistas, 
modificação nos aparatos técnicos e produção de novas teorias - características e enunciados de uma crise e que sempre precedem uma nova teoria.

A simples consciência da anomalia não faz com que os cientistas abandonem um paradigma sem que já se tenha um substituto, pois "rejeitar um paradigma sem simultaneamente substituí-lo por outro é rejeitar a própria ciência” 42 (p. 110). Em outras palavras, a presença de uma anomalia não significa que possam engendrar a emergência de teorias e novos paradigmas. E também, nem toda crise gera mudança paradigmática. Às vezes, a ciência normal acaba se revelando capaz de resolver o problema que provoca a crise. Outras vezes o problema resiste mesmo com novas abordagens. Nesse caso, o problema recebe um rótulo e é posto de lado para ser resolvido posteriormente. Ou ainda, pode disparar a emergência de um novo paradigma.

Hunter 43 indaga a medicina sob a luz da epistemologia kuhniana e afirma que na prática clínica a proporção entre a atividade "comum" e "revolucionária" difere da produção das ciências naturais. Detalhes fora do padrão e observações de fatos que "não se encaixam" são muito mais frequentes na prática médica do que na Física, Química ou mesmo na Biologia. Quando a ideia paradigmática é aplicada ao raciocínio do processo diagnóstico, percebe-se uma constante necessidade de rever hipóteses frente às queixas trazidas por cada paciente. Diante de cada caso, há sempre a possibilidade de anomalias que não cabem completamente nas categorizações de doenças.

Guedes et al. 37 também recorreram ao pensamento de Kuhn ao analisarem como as manifestações somáticas (somatizações ou queixas dificilmente enquadráveis nos diagnósticos "tradicionais") são abordadas como anomalias pela Biomedicina.

Nesse cenário em que figuram as tecnobiociências e reificam as evidências científicas, propor um debate sobre o ensino da comunicação com base na produção de subjetividades e na reflexão sobre valores desejáveis para a atuação no campo da saúde - para além dos protocolos ou da padronização dos modos de se praticar a clínica - é, em certa medida, apostar em uma anomalia.

Como fugir do Uncanny Valley? Como permitir que o ensino sobre comunicação clínica seja um questionador do modelo reducionista e "objetificante" da Biomedicina? Como evitar que o treinamento de habilidades comunicacionais nos torne burocratas repetidores de frases feitas?

O currículo de comunicação é importante em todos os níveis de formação, incluindo graduação, pós-graduação e educação permanente. Pela complexidade inerente ao tema, sempre se pode permitir espaços de ensino-aprendizagem para o exercício da comunicação clínica ${ }^{13}$. No entanto, espera-se que esses espaços, para além das ferramentas e técnicas de abordagem mais instrumental, possibilitem a reflexão crítica por parte dos sujeitos e o exercício do pensamento sobre a própria racionalidade médico-científica.

A inclusão de disciplinas chamadas "Humanidades Médicas" - área que aglutina saberes da Filosofia, Bioética, Psicologia, Antropologia, Artes, Sociologia, História e Política, no âmbito da medicina foi ganhando espaço nas discussões de reformas curriculares no Brasil e no mundo 44 . Visitas a museus de arte, debates com a utilização de filmes e o estímulo para que estudantes de medicina participem de atividades comunitárias são exemplos de ações propositivas cujo objetivo seria "formar médicos com competência ética e relacional, e superar o pouco produtivo antagonismo entre tecnicismo e humanismo" 44 (p. 1726).

A Extensão Universitária também está inserida no conjunto de espaços pedagógicos em que o ensino da comunicação clínica aponta para o desenvolvimento de conhecimentos, habilidades e atitudes condizentes com os princípios do SUS, mas também com valores desejáveis para a atuação no campo da saúde, tais como solidariedade, empatia e reflexão crítica 45.

Podemos mencionar ainda o emergente debate da Medicina Narrativa, que tem situado em relevância a necessidade de maior porosidade da prática clínica a contribuições de outras áreas do saber como a Literatura, a Narratologia e, mesmo, a Comunicação. Diversos autores 46,47,48 explicitam a Medicina Narrativa como uma prática e uma disposição intelectual que permite aos médicos perceberem para além dos mecanismos biológicos. Busca-se somar à leitura de sinais do corpo uma decodificação das narrativas e outros indícios verbais e não verbais dos pacientes, e uma consciência dos aspectos éticos e contextuais envolvidos. Tal habilidade requer uma abertura não apenas cognitiva, mas também, da esfera dos valores na experiência do encontro clínico. Nesse sentido, o intuito é amplificar os elementos do universo interpretativo do clínico para ser capaz de reconhecer os con- 
textos narrativos em que falas, significados e demandas dos pacientes sejam concebidos para além da engessada anamnese médica.

Embora se reconheça que todas as disciplinas médicas, na prática, precisam se referenciar nos saberes humanísticos para produzir um cuidado integral, segundo Rego ${ }^{34}$, o ensino das humanidades encontra resistências mesmo dentro das escolas médicas, em especial na integração das disciplinas que dizem respeito "ao corpo e à alma”. Rios 44 aponta que as resistências às disciplinas de humanidades no curso de medicina se expressam como: preconceito e desinteresse dos alunos por assuntos que não são considerados diretamente ligados à prática clínica; aulas tidas como demasiado teóricas e descontextualizadas do momento do aprendizado do aluno; falta de professores preparados para desenvolver a aprendizagem em pequenos grupos; dissociação entre o que se discute nas disciplinas de humanidades e o comportamento dos professores de outras disciplinas práticas; e a falta de reconhecimento institucional da área de humanidades no ensino médico.

Tais proposições talvez possam ser reconhecidas como vetores de desorganização ou linhas de fuga deleuzianas, pois indicam reformulações mestiças e insurgentes, inquietantes do ponto de vista do exercício de uma análise crítica, assim como relevantes no contexto de onde surgem; e ainda, proclamam a necessidade de produzir brechas, rachaduras, para tornar mais porosas as fronteiras e arenas acadêmicas e científicas às anomalias fugitivas da padronização.

Tal e qual, a anomalia da personagem Lisa é perturbadora da ordem estabelecida na ficção. Mas per se não garante a mudança de "paradigma", no sentido de modelo dominante do contexto imaginado pelos diretores do filme. Como uma anomalia, Lisa mais parece repelida que aceita pelos pares. Mas resiste, produzindo sua existência singular.

\section{Colaboradores}

B. P. Stelet foi responsável pela concepção e projeto do texto, atuou na redação, revisão crítica relevante do conteúdo e aprovação final da versão a ser publicada. L. D. Castiel e D. R. Moraes atuaram na redação do texto, revisão crítica relevante do conteúdo e aprovação final da versão a ser publicada. 


\section{Referências}

1. Deleuze G. Conversações: 1972-1990. São Paulo: Editora 34; 1992.

2. Araújo IS, Cardoso JM. Comunicação e saúde. Rio de Janeiro: Editora Fiocruz; 2007.

3. Associação Brasileira de Saúde Coletiva. GT de Comunicação e Saúde. http://www.abrasco. org.br/site/gtcomunicacaoesaude/ (acessado em 24/Out/2015).

4. Araújo IS, Cardoso JM. Comunicação e saúde: os princípios do SUS como ponto de vista. In: Pinheiro R, Mattos RA, organizadores. Cuidar do cuidado: responsabilidade com a integralidade das ações em saúde. Rio de Janeiro: Centro de Estudos e Pesquisa em Saúde Coletiva/ Associação Brasileira de Saúde Coletiva; 2008. p. 61-78.

5. Araújo IS. Reflexões inquietas sobre a comunicação, as fronteiras e o cuidado. In: Pinheiro R, Silveira R, Lofego J, Silva Junior AG, organizadores. Integralidade sem fronteiras: itinerários de justiça, formativos e de gestão na busca por cuidado. Rio de Janeiro: Centro de Estudos e Pesquisa em Saúde Coletiva/Associação Brasileira de Saúde Coletiva; 2012. p. 127-38.

6. Campos GWS. Equipes de referência e apoio especializado matricial: um ensaio sobre a reorganização do trabalho em saúde. Ciênc Saúde Coletiva 1999; 4:393-403.

7. Campos GS. Saúde Paidéia. São Paulo: Editora Hucitec; 2003.

8. Campos GWS. A mediação entre conhecimento e práticas sociais: a racionalidade da tecnologia leve, da práxis e da arte. Ciênc Saúde Coletiva 2011; 16:3033-40.

9. Pinheiro R, Mattos RA, organizadores. Razões públicas para a integralidade em saúde: o cuidado como valor. Rio de Janeiro: Centro de Estudos e Pesquisa em Saúde Coletiva/Associação Brasileira de Saúde Coletiva; 2007.

10. Ayres JRCM. Cuidado: trabalho e interação nas práticas de saúde. Rio de Janeiro: Centro de Estudos e Pesquisa em Saúde Coletiva/Associação Brasileira de Saúde Coletiva; 2009.

11. Ministério da Educação. Resolução no 3, de 20 de junho de 2014. Institui diretrizes curriculares nacionais do curso de graduação em Medicina e dá outras providências. Diário Oficial da União 2014; 23 jun.

12. Dohms MC. Ensino-aprendizagem da comunicação médico-paciente, na percepção de estudantes, em uma escola brasileira e duas europeias: desafios e perspectivas para a educação médica brasileira [Dissertação de Mestrado]. Florianópolis: Universidade Federal de Santa Catarina; 2011.
13. Kurtz S, Silverman J, Draper J. Teaching and learning communication skills in medicine. 2nd Ed. Oxford: Radcliffe Medical Press; 2005.

14. Carrió FB. Entrevista clínica: habilidades de comunicação para profissionais de saúde. Porto Alegre: Editora Artmed; 2012.

15. Mattos RA. Os sentidos da Integralidade: algumas reflexões acerca de valores que merecem ser definidos. In: Pinheiro R, Mattos RA, organizadores. Os sentidos da integralidade na atenção e no cuidado à saúde. Rio de Janeiro: Centro de Estudos e Pesquisa em Saúde Coletiva/Associação Brasileira de Saúde Coletiva; 2001. p. 39-64.

16. Baumhardt VC. Personagem e narrativa no documentário "jogo de cena” [Dissertação de Mestrado]. Porto Alegre: Pontifícia Universidade Católica do Rio Grande do Sul; 2011.

17. Kaufman C, Johnson D. Anomalisa [DVD]. Tran R, Johnson D, Kaufman C, Stamatopoulos C, produtores. Los Angeles: Paramount Pictures; 2015. 1 DVD: 90 min., som, cor, 4 3/4 pol.

18. Foucault M. Em defesa da sociedade: curso no Collège de France (1975-1976). São Paulo: Editora Martins Fontes; 2005.

19. Pelbart PP. Políticas da vida, produção do comum e a vida em jogo... Saúde Soc 2015; 24 Suppl 1:19-26.

20. Castiel LD, Sanz-Valero J, Vasconcelos-Silva PR. Das loucuras da razão ao sexo dos anjos: biopolítica, hiperprevenção, produtividade científica. Rio de Janeiro: Editora Fiocruz; 2011.

21. Foucault M. História da sexualidade I: a vontade de saber. São Paulo: Edições Graal; 2010.

22. Rabinow P, Rose N. Biopower today. Biosocieties 2006; 1:195-217.

23. Foucault M. Segurança, território, população. Curso no Collège de France (1977-1978). São Paulo: Editora Martins Fontes; 2008.

24. Beck U. La sociedad del riesgo mundial: en busca de la seguridad perdida. Buenos Aires: Paidós; 2008.

25. Mathur MB, Reichling DB. Navigating a social world with robot partners: a quantitative cartography of the Uncanny Valley. Cognition 2016; 146:22-32. 
26. MacDorman KF, Chattopadhyay D. Reducing consistency in human realism increases the uncanny valley effect: increasing category uncertainty does not. Cognition 2016; 146:190-205.

27. Gardner C. Medicine's uncanny valley: the problem of standardising empathy. Lancet 2015; 386:1032-3.

28. Baile WF, Buckman R, Lenzia R, Glober G, Beale EA, Kudelkab AP. SPIKES - a six-step protocol for delivering bad news: application to the patient with cancer. Oncologist 2000; 5:302-11.

29. Lino CA. Uso do protocolo Spikes no ensino de habilidades em transmissão de más notícias. Rev Bras Educ Med 2011; 35:52-7.

30. Schweller M. O ensino de empatia no curso de graduação em medicina [Tese de Doutorado]. Campinas: Faculdade de Ciências Médicas, Universidade Estadual de Campinas; 2014.

31. Hojat M, Vergare MJ, Maxwell K, Brainard G, Herrine SK, Isenberg GA, et al. The devil is in the third year: a longitudinal study of erosion of empathy in medical school. Acad Med 2009; 84:1182-91.

32. Eisenberg N, editor. Empathy and related emotional response. San Francisco: Jossey-Bass; 1989.

33. Aranha ML. A filosofia da educação. 2a Ed. São Paulo: Moderna; 1990.

34. Rego SA. Formação ética dos médicos: saindo da adolescência com a vida (dos outros) nas mãos. Rio de Janeiro: Editora Fiocruz; 2005.

35. Silva TT. Documento de identidade: uma introdução às teorias do currículo. Belo Horizonte: Autêntica; 1999.

36. Bonet O. O saber e o sentir: uma etnografia da aprendizagem da biomedicina. Physis (Rio J.) 1999; 9:123-50.

37. Guedes CR, Nogueira MI, Camargo Jr. KR. A subjetividade como anomalia: contribuições epistemológicas para a crítica do modelo biomédico. Ciênc Saúde Coletiva 2006; 11:1093-103.

38. Schraiber LB. Racionalidade biomédica e transformações históricas da prática medica ao longo do século XX: breves apontamentos para a reflexão crítica. In: Pinheiro R, Silva Junior AG, organizadores. Por uma sociedade cuidadora. Rio de Janeiro: Centro de Estudos e Pesquisa em Saúde Coletiva/Associação Brasileira de Saúde Coletiva; 2010. p. 115-28.
39. Canguilhem G. O normal e o patológico. 6a Ed. Rio de Janeiro: Forense Universitária; 2009.

40. Czeresnia D. Categoria vida: reflexões para uma nova biologia. São Paulo: Editora Unesp/ Rio de Janeiro: Editora Fiocruz; 2012.

41. Dardot P, Laval C. A nova razão do mundo: ensaio sobre a sociedade neoliberal. São Paulo: Boitempo; 2016.

42. Kuhn T. A estrutura das revoluções científicas. São Paulo: Perspectiva; 2003.

43. Hunter KM. Doctor's stories: the narrative structure of medical knowledge. Princeton: University of Princeton Press; 1991.

44. Rios IC. Humanidades e medicina: razão e sensibilidade na formação médica. Ciênc Saúde Coletiva 2010; 15 Suppl 1:1725-32.

45. Stelet BP. Sobre repercussões de atividades extensionistas na construção de valores e virtudes durante a formação em medicina [Dissertação de Mestrado]. Rio de Janeiro: Instituto de Medicina Social, Universidade do Estado do Rio de Janeiro; 2013.

46. Hurwitz B, Greenhalgh T. Narrative-based medicine: dialogue and discourse in clinical practice. London: BMJ Books; 1998.

47. Favoreto CAO, Camargo Jr. KR. A narrativa como ferramenta para o desenvolvimento da prática clínica. Interface Comun Saúde Educ 2011; 15:473-83.

48. Charon R. Narrative medicine: honoring the stories of illness. Oxford: Oxford University Press; 2006. 


\section{Abstract}

Based on reflections on the film Anomalisa and Foucault's concept of biopower, this essay discusses the limits of teaching clinical communication skills in medical training. Communication with patients is not related to the use (or lack thereof) of certain phrases or a given conversational style, but involves the search for a way of interacting with the other in the midst of the world's disorder, the overwhelming wave of suffering, and the frightening lapse of time between life and death. In this scenario featuring biotechnoscience and the reign of scientific evidence, beyond protocols or standardized ways of practicing medicine, the proposal here is for a debate on teaching communication with an emphasis on the production of subjectivities, in order to issue a call for reflection on desirable values for action in the health field.

Health Communication; Medical Education; Physician-Patient Relations

\section{Resumen}

Partiendo de las reflexiones de la película Anomalisa, y apoyándose en el concepto foucaultiano de biopoder, este ensayo discute los limites de la enseñanza de habilidades de comunicación clinica en la formación en medicina. La comunicación con pacientes no se relaciona con el uso (o no-uso) de ciertas frases o de un determinado estilo de conversación, sino que significa la búsqueda de una manera de interactuar con el prójimo, en medio del caos del mundo, la arrebatadora ola de sufrimiento y el intervalo de tiempo aterrador entre la vida y la muerte. Es en ese escenario donde se ubican las tecnobiociencias e imperan las evidencias científicas, en el que además de los protocolos o de la estandarización de los modos de práctica clinica, se propone un debate sobre la enseñanza de la comunicación, con énfasis en la producción de subjetividades, de modo que se viabilice un llamamiento a la reflexión sobre valores deseables para la actuación en el campo de la salud.

Comunicación en Salud; Educación Médica; Relaciones Médico-Paciente
Recebido em 02/Set/2016

Versão final reapresentada em 01/Nov/2016

Aprovado em 28/Nov/2016 